\title{
Prenatal Diagnosis of Congenital Cystic Adenomatoid Malformation of the Lung
}

\author{
Raja Briki, Ons Cherif*, Mouna Derouich, Anouar Chaieb and Mohamed Bibi \\ Department of Gynecology and Obstetrics, Farhat Hached University Hospital, Tunisia
}

Submission: October 01, 2018; Published: October 11, 2018

*Corresponding author: Ons Cherif, Department of Gynecology and Obstetrics, Farhat Hached University Hospital, Sousse, Tunisia, Email: ons.cherifb@gmail.com

Abstract

Congenital cystic adenomatoid malformation (CCAM) of the lung is rare. Its diagnosis is based on antenatal ultrasound and sometimes MRI. Natural course and prognosis may be favorable, but the appearance of complications, especially the fetal hydrops, is possible even quite common. We report four cases of CCAM diagnosed in the second trimester of pregnancy. Only one case was born. We propose to evaluate the contribution of prenatal ultrasonography in the diagnosis of this type of malformation.

Keywords: Antenatal ultrasound; Pulmonary lesions; Fetopathological entity; Morphological; Amenorrhea; Hyperechoic mass

Abbreviations: CCAM: Congenital Cystic Adenomatoid Malformation; MRI: Magnetic Resonance Imaging; TTP: Therapeutic Termination of Pregnancy

\section{Introduction}

Congenital cystic adenomatoid malformations (CCAM) are relatively rare developmental abnormalities of the lung [1]. They correspond to distal bronchial and pulmonary cystic dilations, communicating with the bronchial tree and devoid of cartilaginous rings [2]. They represent $25 \%$ of congenital pulmonary lesions [3].

Prenatal diagnosis has become easier with the higher resolution ultrasound imaging and has profoundly changed the management of this fetopathological entity. We report a series of four diagnosed CCAM cases in our maternity center at Farhat Hached University Hospital in Sousse, Tunisia. It was a retrospective study in order to evaluate the contribution of antenatal ultrasound in the diagnosis of this type of malformation.

\section{Case Study}

Average age of our patients was 28 years, and the mean age of discovery of the abnormality was 23 weeks of amenorrhea. Morphological ultrasound allowed diagnosis in all cases (Figure 1 ), and fetal magnetic resonance imaging (MRI) helped us in two cases.

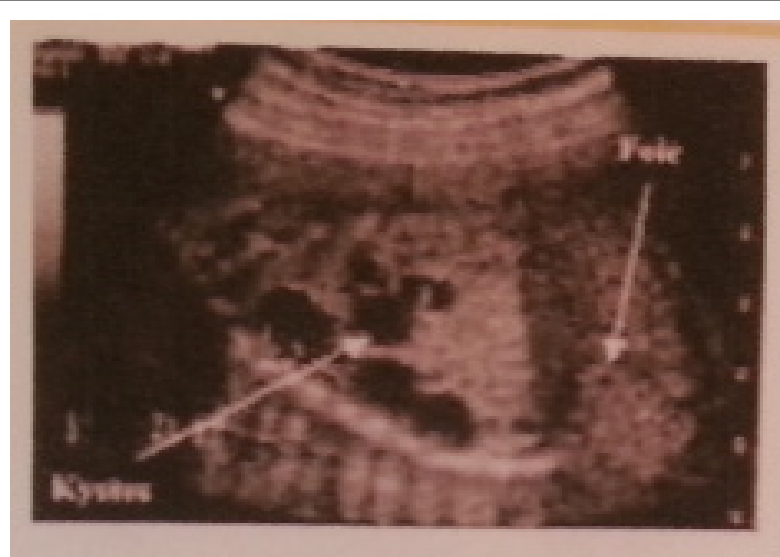

Figure 1: Antenatal ultrasound appearance of a CCAM of the lung.

CCAM was associated with hydrops fetalis in two cases, and a cardiac malformation (interventricular communication type) in one case. Only one pregnancy was completed by refusal of therapeutic termination of pregnancy (TTP). Indication of the TTP was raised in three cases due to the severity of the pulmonary involvement and was accepted by the parents. 


\section{Juniper Online Journal of Case Studies}

The expulsion had occurred at approximately 23 weeks gestation; they were two male fetuses and one female fetus. On the fetopathological examination, no dysmorphic syndrome was found, and the histological analysis of the lungs confirmed the disease in the three cases.

Regarding the term pregnancy, ultrasound chest highlighted at birth, dilation of the upper lobe of the left lung with a heterogeneous echo-texture and a hyperechoic mass in which it was revealed a cystic image. There was also a second cystic image of $4 \mathrm{~mm}$ at the anterior part of the upper lobe of the left lung.
Abdominal ultrasound did not find renal structure in the lumbar lodges but in lumbar-pelvic region, there was macroscopic cystic pictures passing bridge in front of the spine.

The newborn died around the $6^{\text {th }}$ hour of life. The fœtopathological examination showed in the upper lobe the presence of a nodule occupying the dome measuring $2.2 \mathrm{~cm}$ in its largest axis, and micro-cystic appearance at the cut. The inferior lobe was also the site of a spongy-shaped para-hilar nodule measuring $0.5 \mathrm{~cm}$ in its largest axis (Figure 2).
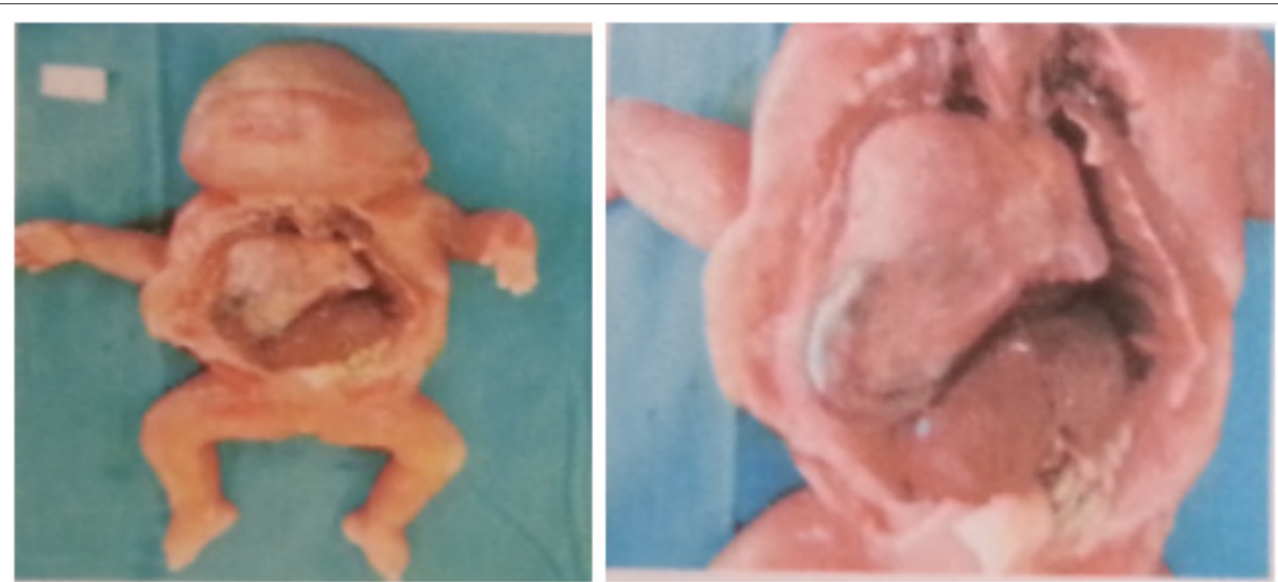

Figure 2: Macroscopic appearance of a CCAM of the lung.
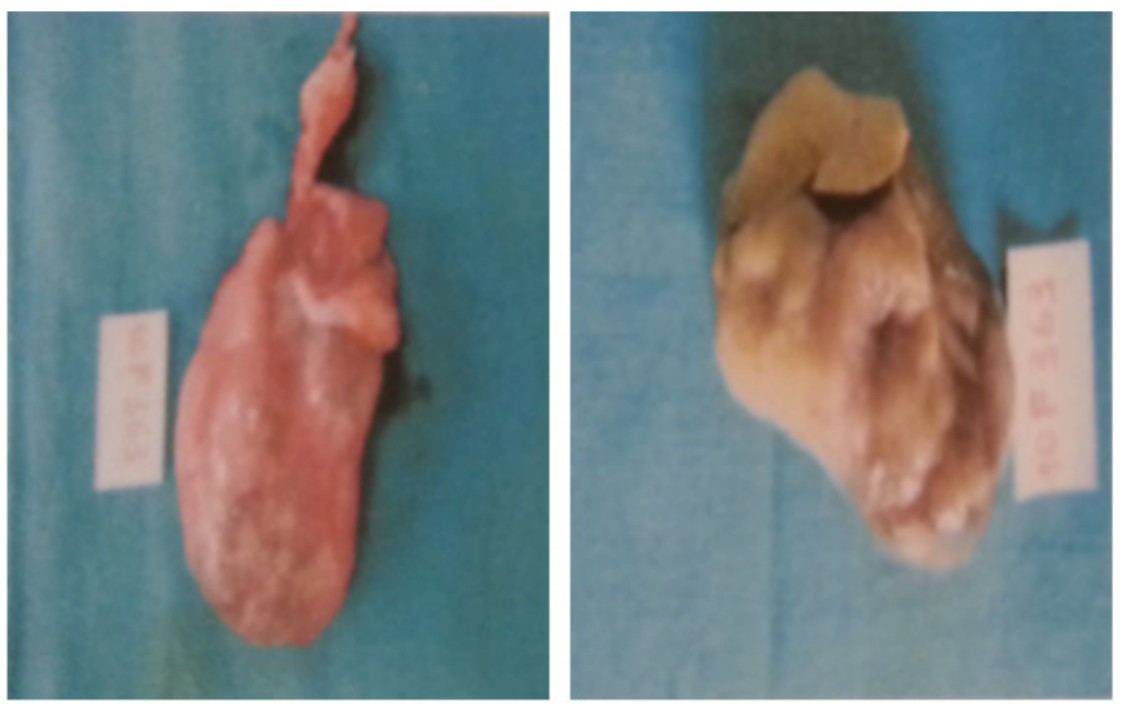

Figure 3: Multiple cystic formations of variable size defining the CCA.

At the microscopic examination, and in the level of these two left lung lobes, there were several cystic formations of variable size between which there were tubular formations of the fetal lung (Figure 3). In the right upper lobe, the same lesions were found as those described on the left side. The lungs were therefore the site of a cystic adenomatoid malformation, multi-focal and bilateral.

\section{Discussion}

Congenital cystic adenomatoid malformation (CCAM) of the lung is a hamartomatous lesion characterized by cystic degeneration of the terminal bronchiolar tissue. Its incidence is estimated at $1 / 25000$ to $1 / 35000$ pregnancies [3].

CCAM is most often diagnosed in the perinatal period but can be detected, in some cases, during infancy and adolescence and even in adulthood [4]. Only the histological study confirms the diagnosis and eliminates other cystic pulmonary malformations. It shows cysts with air or fluid content, limited by a wall devoid of cartilage and without inflammatory signs, lined by an epithelium consisting of ciliated pseudo-stratified cells and mucus cells [2]. 
There are classically three types according to the histological classification of Stocker [2] based essentially on the size of the cysts: type I macrocystic (2 to $10 \mathrm{~cm}$ ) (65\%), type II cystic (up to $2 \mathrm{~cm}$ ) (20 to $35 \%$ ) and type III microcystic (less than $0.5 \mathrm{~cm}$ ) $(10 \%)$ [2].

In prenatal, we use an ultrasound classification distinguishing between microcystic forms (53\%), macrocystic (22\%) or mixed forms (25\%) [5]. MRI can better visualize this malformation, confirm the diagnosis in difficult situations and to share with the various differential diagnoses.

In 80 to $95 \%$ of cases, the CCAM affects only one lobe, with a certain tropism for the right lung [4]. Multiple lobe extension may occur, but bilateral involvement is extremely rare. Our case, having been delivered at term, has the peculiarity of demonstrated this bilateral and multiple involvement of the pulmonary lobes.

Cases of association with other morphological abnormalities have been reported; it may be cardiac, cerebral, diaphragmatic or renal malformations. Adenomatoid lesions are rarely associated with renal abnormalities; it is mainly renal agenesis or dysgenesis.

Prenatal evolution of CCAM is variable: it can lead to fetal hydrops in $40 \%$ or completely regress in $15 \%$ of cases [6].

The management varies according to the time of diagnosis. In the antenatal period, clinical and ultrasound obstetric surveillance is required. The study of fetal karyotype is indicated [7]. Resection or drainage of intrauterine cysts in case of CCAM complicated with fetal hydrops may be indicated. In the absence of means, a therapeutic interruption of the pregnancy can be justified in lethal forms. After birth and regardless of age, surgical resection is required in symptomatic forms [8].

This work is licensed under Creative Commons Attribution 4.0 License DOI: 10.19080/JOJCS.2018.08.555748

\section{Conclusion}

Congenital cystic adenomatoid malformation of the lung is evoked and frequently diagnosed by antenatal ultrasound. Its prognosis depends on the extent of lesions, associated malformations and hemodynamic repercussions.

\section{References}

1. Di Prima FAF, Bellia A, Inclimona G, Grasso F, Teresa M, et al. (2012) Antenatally diagnosed congenital cystic adenomatoid malformations (CCAM): Research Review. J Prenat Med 6(2): 22-30.

2. Stocker JT, Madewell JE, Drake RM (1977) Congenital cystic adenomatoid malformation of the lung: classification and morphologic spectrum. Hum Pathol 8(2): 155-171.

3. Laberge JM, Flageole H, Pugash D, Khalife S, Blair G, et al. (2001) Outcome of the prenatally diagnosed congenital cystic adenomatoid lung malformation: a Canadian experience. Fetal Diagn Ther 16(3): 178-186.

4. Oh BJ, Lee JS, Kim JS, Lim CM, Koh Y (2006) Congenital cystic adenomatoid malformation of the lung in adults: clinical and CT evaluation of seven patients. Respirology 11(4): 496-501.

5. Cavoretto P, Molina F, Poggi S, Davenport M, Nicolaides KH (2008) Prenatal diagnosis and outcome of echogenic fetal lung lesions. Ultrasound Obstet Gynecol 32(6): 769-783.

6. Shanmugam G (2005) Adult congenital lung disease. Eur J Cardio Thoacic Surg 28(3): 483-489.

7. Adzick NS, Harrison MR, Crombleholme TM, Flake AW, Howell LJ (1998) Fetal lung lesions: management and outcome. Am J Obstet Gynecol 179(4): 884-889.

8. Harada K, Noguchi T, Miura T, Kawano Y, Kashima K, et al. (2005) Successful treatment of an adult patient with pulmonary abscess secondary to congenital cystic adenomatoid malformation. Jpn J Thorac Cardiovasc Surg 53(10): 580-582.

\section{Your next submission with Juniper Publishers will reach you the below assets}

- Quality Editorial service

- Swift Peer Review

- Reprints availability

- E-prints Service

- Manuscript Podcast for convenient understanding

- Global attainment for your research

- Manuscript accessibility in different formats

( Pdf, E-pub, Full Text, Audio)

- Unceasing customer service

Track the below URL for one-step submission https://juniperpublishers.com/online-submission.php 